\title{
ИССЛЕДОВАНИЕ АБСОРБЦИИ УГЛЕКИСЛОГО ГАЗА В ВОЛОКНИСТОМ ТУМАНОУЛОВИТЕЛЕ
}

\author{
Арнольд Вальдберг, Евгения Полиенова \\ Московский государственный университет инженерной экологии, \\ Старая Басманная ул., 21/4, 105066 Москва, Россия \\ Эл. nочта: waldberg@inbox.ru \\ Поступила 27 апреля 2009 г.; принята 22 сентября 2009 г.
}

\begin{abstract}
Резюме. Промышленные испытания волокнистых фильтров показали, что помимо улавливания капель туманов, они достаточно эффективно поглощают и газообразные вредности. В связи с этим на экспериментальной установке, основным элементом которой являлся аппарат с волокнистой насадкой, были проведены исследования, позволившие получить количественные результаты по абсорбции $\mathrm{CO}_{2}$ водным раствором соды. Исследования абсорбера проводились в лаборатории кафедры «Инженерная экология городского хозяйства» Московского государственного университета инженерной экологии (МГУИЭ). Экспериментальная установка автоматизирована: контроль и регулировка режимных параметров абсорбера осуществляются с экрана персонального компьютера.
\end{abstract}

Ключевые слова: волокнистая насадка, гидравлическое сопротивление, абсорбция.

\section{1. Введение}

Одним из последствий техногенного влияния на окружающую среду в настоящее время является заметное ухудшение состояния атмосферного воздуха. Основными источниками загрязнения служат промышленные предприятия, транспорт, тепловые электростанции, животноводческие комплексы. Каждый из этих источников связан с выделением большого количества специфических токсичных веществ, различающихся по фазовому и химическому составу.

Известно, что значительная доля выбросов приходится на газообразные вредности.

Из газообразных загрязнителей наиболее крупнотоннажные (млн. т в год) глобальные загрязнения атмосферы образуют следующие вещества: $\mathrm{CO}_{2}$ $\left(2 \cdot 10^{4}\right), \mathrm{CO}(200), \mathrm{SO}_{2}(150)$, углеводороды $(>50), \mathrm{NO}_{\mathrm{x}}$ (50).

Для улавливания газообразных токсичных компонентов из отходящих газов используют абсорбционные, адсорбционные, каталитические и термические методы. Выбор метода очистки зависит от количества и состава отходящих газов, от необходимой степени очистки. Наиболее широкое применение нашли абсорбционные методы (Страус 1981; Торочешников $u$ дp. 1981; Кутепов $u$ дp. 2003; Родионов $u \partial p$. 2005), которые осуществляются в насадочных колоннах (Ужов $и$ др. 1972; Леонтьев $u$ дp. 2005; Лаптев $u$ дp. 2006; Krasovickij et al. 2006; Пушнов $u$ $\partial p$. 2008), обеспечивающих высокоразвитую поверхность контакта фаз. Для достижения высоких степеней улавливания очистку производят различными хемосорбентами (Вальдберг и др. 2008).
Волокнистые фильтры-туманоуловители получили широкое применение при улавливании взвешенных капель (Вальдберг $u$ дp. 2003). В процессе испытаний волокнистых туманоуловителей в промышленности была отмечена и их достаточно высокая эффективность при улавливании хорошо растворимых газовых примесей (паров $\mathrm{HCl}$ ). При скорости газового потока 1,1-1,2 м/с были получены значения объемного коэффициента абсорбции $K_{y}$ порядка 3000-7000 1/ч (Вальдберг и др. 2004).

В связи с этим возникло предположение о возможности комплексного использования волокнистых туманоуловителей для улавливания как взвешенных капель, так и газообразных примесей, причем не только хорошо растворимых.

В МГУИЭ были проведены исследования разработанного на базе конструкции волокнистого туманоуловителя типа СННК экспериментального абсорбера с волокнистой насадкой производительностью до $1000 \mathrm{~m}^{3} /$ ч на примере поглощения $\mathrm{CO}_{2}$ водным раствором соды.

\section{2. Экспериментальная установка и методики проведения испытаний}

Абсорбер (рис. 1) представляет собой горизонтально расположенный аппарат квадратного сечения.

В абсорбере поперек газового потока установлено шесть кассет с насадкой, последняя из которых по ходу газа не орошается жидкостью и играет роль каплеуловителя, предотвращающего унос абсорбента очищенным газом. В качестве насадки применены кассеты с металлической сеткой трикотажного плетения (рис. 2). Диаметр нити сетки составляет 0,3 мм. К 


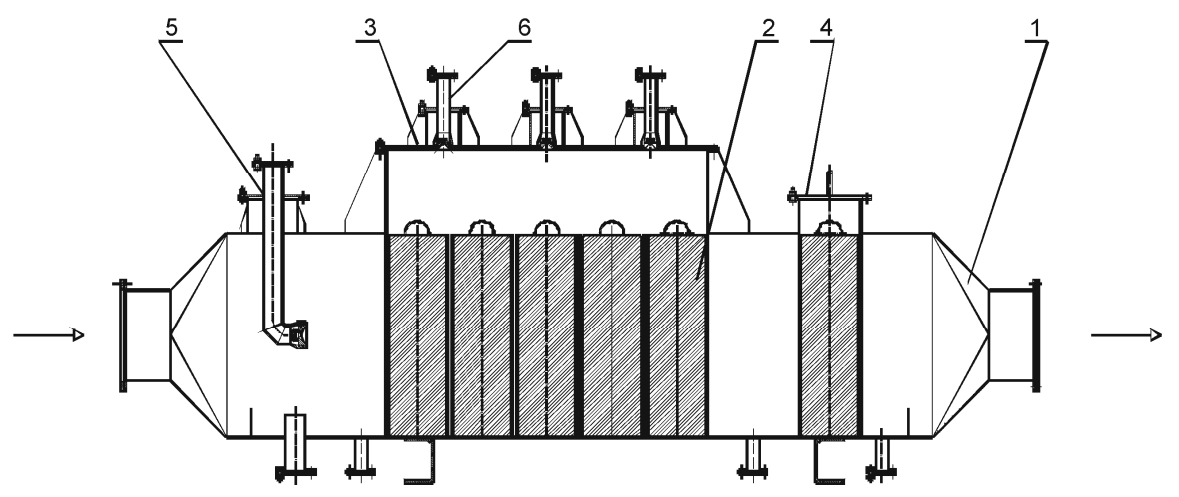

Рис. 1. Общий вид абсорбера с волокнистой насадкой: 1 - корпус; 2 - кассета; 3, 4 - крышка; 5 - подвод $\mathrm{D}_{\mathrm{y}} 40 ; 6$ - подвод $\mathrm{D}_{\mathrm{y}} 25$

Fig. 1. Absorber with fibrous nozzle: general view: 1 - corpus; 2 - cassette; 3, 4-cover; 5-supply of $\mathrm{D}_{\mathrm{y}} 40 ; 6$ - supply of $\mathrm{D}_{\mathrm{y}} 25$

достоинствам кассеты относится простота изготовления и развитая поверхность насадки. Металлическая сетка трикотажного плетения закреплена на каркасе. Пять первых по ходу газа кассет орошаются вертикальными потоками абсорбента через три расположенные над ними форсунки (зона абсорбции). Кроме того, в конструкции аппарата предусмотрено орошение перед слоем насадки, предназначенное для предварительной очистки выбросов от капель туманов. Орошение аппарата осуществляется центробежными цельнофакельными форсунками.
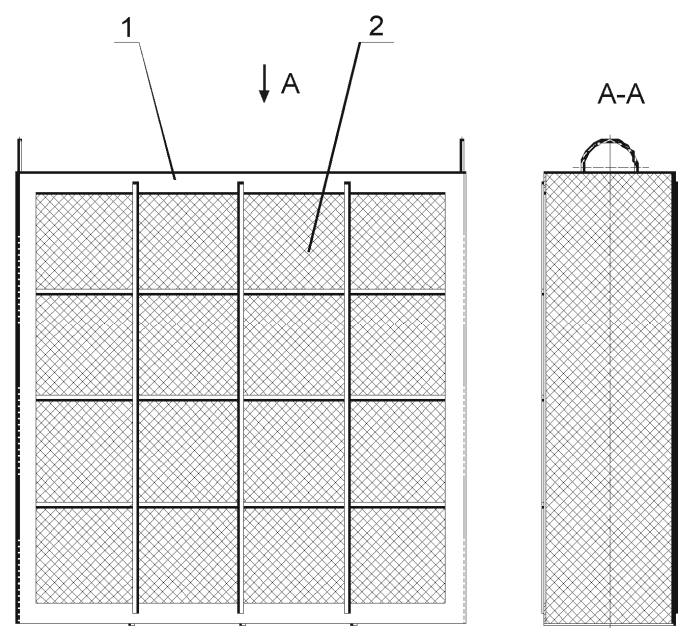

Рис. 2. Кассета с металлической сеткой трикотажного плетения: 1 - каркас; 2 - сетка

Fig. 2. Cassette with metal mesh of knitted weave: $1-$ framework; 2 - mesh

Схема экспериментальной установки представлена на рис. 3 .

Работа экспериментальной установки осуществляется следующим образом.

Газовый поток, представляющий собой смесь воздуха и углекислого газа, проходит через абсорбер в горизонтальном направлении. Углекислый газ подается из стального баллона в тот же газоход, что и воздух. Концентрация $\mathrm{CO}_{2}$ в газовом потоке не пре- вышает $0,5 \%$ об. $\left(9,90 \Gamma / \mathrm{M}^{3}\right)$. В результате контакта газа и жидкости происходит хемосорбция $\mathrm{CO}_{2}$ (Коуль и др. 1967):

$$
\mathrm{Na}_{2} \mathrm{CO}_{3}+\mathrm{CO}_{2}+\mathrm{H}_{2} \mathrm{O} \leftrightarrow 2 \mathrm{NaHCO}_{3} .
$$

Отработанный абсорбент собирается в нижней части абсорбера и удаляется из него через систему гидрозатворов. Гидрозатворы препятствуют подсосу газа из емкости с абсорбентом, обеспечивая тем самым поддержание в аппарате необходимого манометрического режима (давления). Отводимый из аппарата поглотитель направляется в емкость с абсорбентом, где смешивается с рабочим раствором, а абсорбент насосом подается на орошение абсорбера, т. е. работа установки осуществляется по замкнутой схеме с циркуляцией абсорбента.

Условный объемный коэффициент абсорбции $\mathrm{CO}_{2} K_{y}\left(\mathrm{c} / \mathrm{M}^{2}\right)$ определяли из выражения (Вальдберг u дp. 2004):

$$
G=K_{y} \cdot \Delta p^{n} \cdot V,
$$

где: $G$-массовый расход поглощенного $\mathrm{CO}_{2}$, кг/с; $\Delta p^{n}$-движущая сила процесса поглощения, Па; $V$-объем активной зоны аппарата, занимаемый насадкой, $\mathrm{m}^{3}$.

Объем $V$ составлял $0,13 \mathrm{~m}^{3}$.

Массовый расход $G$ определяли по формуле:

$$
G=\frac{\left(z^{\prime}-z^{\prime \prime}\right) \cdot V_{6}}{3600},
$$

где: $z^{\prime}, z^{\prime \prime}$ концентрации $\mathrm{CO}_{2}$ в воздухе на входе в

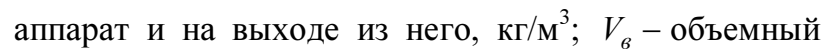
расход очищаемого воздуха, $\mathrm{m}^{3} /$ ч.

Концентрации $z^{\prime}, z^{\prime \prime}$ измеряли с помощью оптико-акустических газоанализаторов типа «Кедр» (ОАО НПО «Химавтоматика»), а расход $V_{6}$ - расходомером переменного перепада (нормальная диафрагма) с двумя измерительными преобразователями перепада давления «Сапфир 2410» (ЗАО «Манометр») с пределами измерения 0-1 кПа и 0-0,16 кПа 


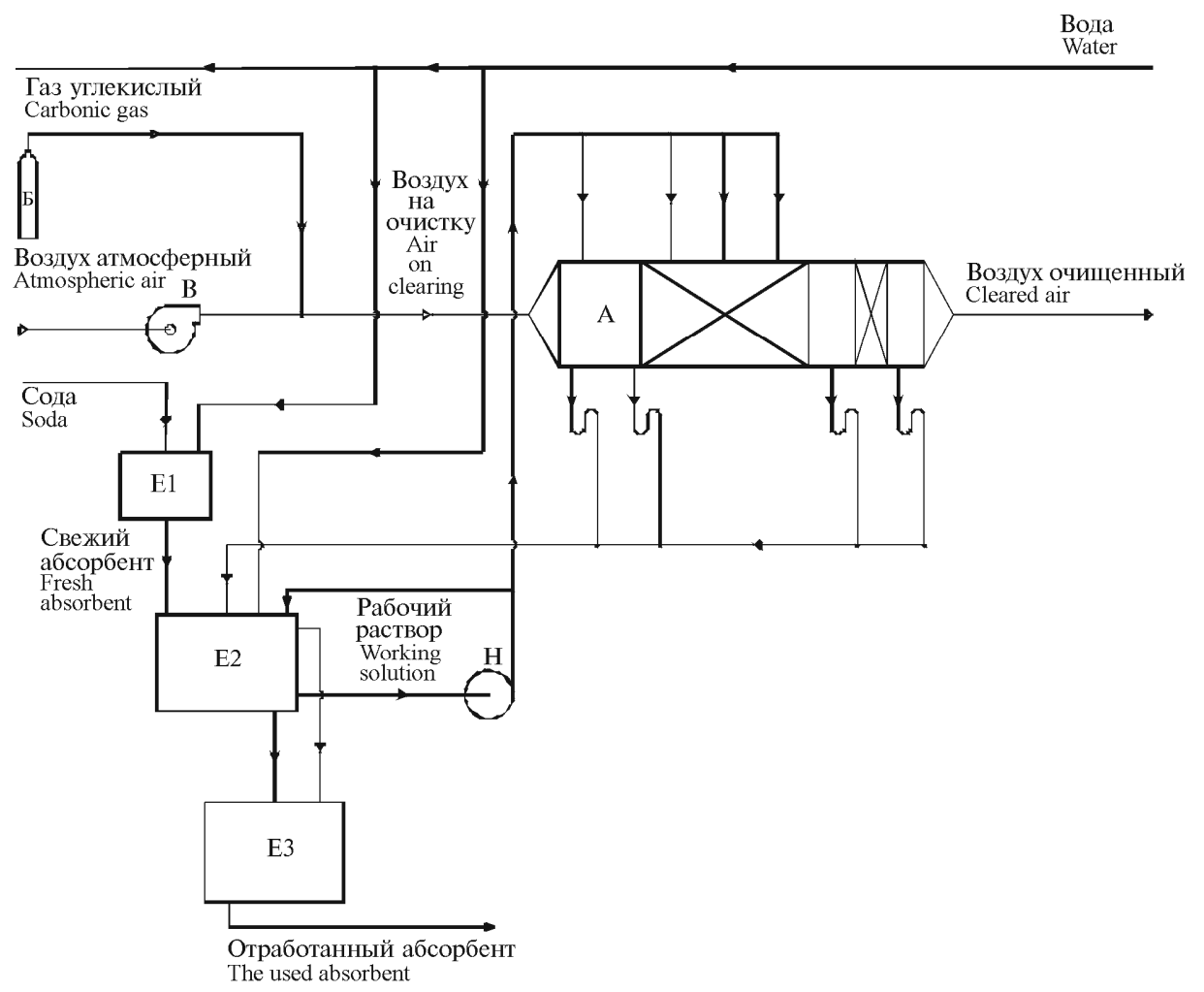

Рис. 3. Схема экспериментальной установки: А - абсорбер с волокнистой насадкой; Б - стальной баллон с углекислым газом; В - вентилятор; E1, E2, Е3 - емкости соответственно со свежим абсорбентом, рабочим раствором, отработанным абсорбентом; $\mathrm{H}$ - насос

Fig. 3. Scheme of experimental plant: A - absorber with fibrous nozzle; $\mathrm{-} \mathrm{steel} \mathrm{balloon}$ with carbon dioxide; B - cooler; E1, E2, E3 - reservoirs with new absorbent, working solution, used absorbent respectively; $\mathrm{H}$ - pump

соответственно. Регулирование расхода воздуха осуществляли изменением положения дисковой поворотной заслонки с электроприводом.

Движущую силу процесса $\Delta p^{n}$ определяли по формуле:

$$
\Delta p^{n}=\frac{p^{\prime}-p^{\prime \prime}}{\ln \frac{p^{\prime}}{p^{\prime \prime}}},
$$

где: $p^{\prime}, p^{\prime \prime}-$ парциальное давление $\mathrm{CO}_{2}$ на входе в аппарат и выходе из него, Па.

Давление $p^{\prime}$ рассчитывали по формуле:

$$
p^{\prime}=\frac{z^{\prime} \cdot p^{\prime}{ }_{6}}{\rho_{6}},
$$

а $p^{\prime \prime}$ по формуле:

$$
p^{\prime \prime}=\frac{z^{\prime \prime} \cdot\left(p_{6}^{\prime}-\Delta p\right)}{\rho_{B}},
$$

где: $p_{6}^{\prime}$-давление воздуха на входе в аппарат (практически соответствует атмосферному давлению), Па; $\Delta p$-гидравлическое сопротивление

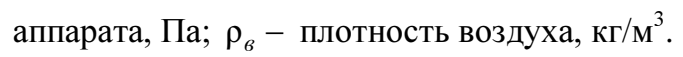

Абсолютное давление $p^{\prime}{ }_{s}$ измеряли измерительным преобразователем абсолютного давления «Сапфир 2040» (ЗАО «Манометр») с пределами измерения 0-160 кПа, а перепад давления $\Delta p-$ измерительным преобразователем абсолютного давления «Сапфир 2410» (ЗАО «Манометр») с пределами измерения 0-1 кПа.

Для сопоставления полученных значений коэффициента $K_{y}$ со значениями условного коэффициента абсорбции хорошо растворимых газов $K_{y}^{\prime}(1 / 4)$ проведен перерасчет по формуле:

$$
K_{y}^{\prime}=\frac{K_{y} \cdot R \cdot T \cdot 3600}{M},
$$

где: $R$ - газовая постоянная, равная 8314 Дж/ (кмоль·К); $T$ - абсолютная температура очищаемого газа, К; $M-$ молярная масса поглощаемого газа, кг/кмоль.

Измерение температуры газа $t_{2}\left({ }^{\circ} \mathrm{C}\right)$ производили термометром сопротивления ТСМУ «Метран-274» («Метран») с унифицированным выходным сигналом в диапазоне от $18^{\circ} \mathrm{C}$ до $45^{\circ} \mathrm{C}$.

Расход орошающей жидкости $V_{ж}$ измеряли с помощью индукционного расходомера ЭРСВ-410. Регулирование расходов орошающей жидкости осуществляется изменением положения электромагнитных клапанов. 
Концентрацию абсорбента на входе в аппарат $C$ измеряли кондуктометром с датчиком «Кварц-2» (ПК «Кварц»).

Измерение температуры орошающей жидкости $t_{ж}\left({ }^{\circ} \mathrm{C}\right)$ производили термометром сопротивления ТСМУ «Метран-274» («Метран») с унифицированным выходным сигналом в диапазоне от $18^{\circ} \mathrm{C}$ до $45^{\circ} \mathrm{C}$.

\section{3. Результаты и их обсуждение}

При проведении исследований измеряли следующие величины:

-объемный расход воздуха $V_{6}$ в диапазоне 100 $1000 \mathrm{~m}^{3} / \mathrm{ч}$

- гидравлическое сопротивление аппарата $\Delta p$ в диапазоне 10-250 Па;

- расход абсорбента через горизонтальную форсунку $V_{\varkappa}^{\text {гор }}$ в диапазоне $0,1-2,0 \mathrm{~m}^{3} / \mathbf{4}$;

- расход абсорбента через вертикальные фор-

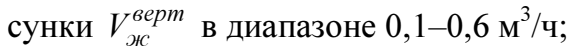

-концентрацию $\mathrm{CO}_{2}$ на входе в аппарат $z^{\prime}$ до $0,5 \%$ об. $\left(9,9 \Gamma / \mathrm{M}^{3}\right)$;

- концентрацию $\mathrm{CO}_{2}$ на выходе из аппарата $z^{\prime \prime}$ до $0,2 \%$ об. $\left(4,0\right.$ г/ $\left.\mathrm{M}^{3}\right)$;

- концентрацию абсорбента на входе в аппарат С до 5,5 г/л.

Для приведения расхода газов к нормальным условиям измеряли также абсолютное давление $p^{\prime}{ }_{6}$ и температуру газов $t_{e}$ на входе в аппарат. Абсолютное давление газов на входе в аппарат $p_{6}^{\prime}$ поддерживали равным около 0,1 кПа.

Температуру газов $t_{2}$ на входе и выходе из аппарата, температуру абсорбента на входе и выходе из аппарата $t_{ж}$ поддерживали в диапазоне $18-20^{\circ} \mathrm{C}$.

В результате исследований были определены гидравлическое сопротивление аппарата и коэффициент абсорбции при различных значениях основных факторов, влияющих на определяемые параметры (линейную скорость газа, расход орошающей жидкости и др.). Было изучено влияние системы орошения аппарата (горизонтальное, вертикальное, комплексное орошение) на эффективность абсорбции.

Обобщенные экспериментальные данные по гидравлическому сопротивлению волокнистого фильтра представлены на рис. 4.

Обобщенные данные по зависимости условного объемного коэффициента абсорбции, $K_{y}^{\prime}, 1 /$ ч, от линейной скорости газов в свободном сечении аппарата, $v_{2}$, $\mathrm{M} / \mathrm{c}$, удельного орошения, $m, \mathrm{~m}^{3} / \mathrm{M}^{3}$, концентрации $\mathrm{CO}_{2}$

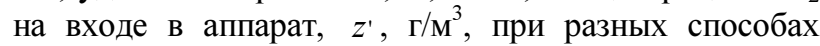
подвода орошения представлены на рис. 5-8.

Полученные данные по гидравлическому сопротивлению аппарата свидетельствуют о его увеличении с возрастанием скорости газа в свободном сечении аппарата и расхода жидкости на орошение.

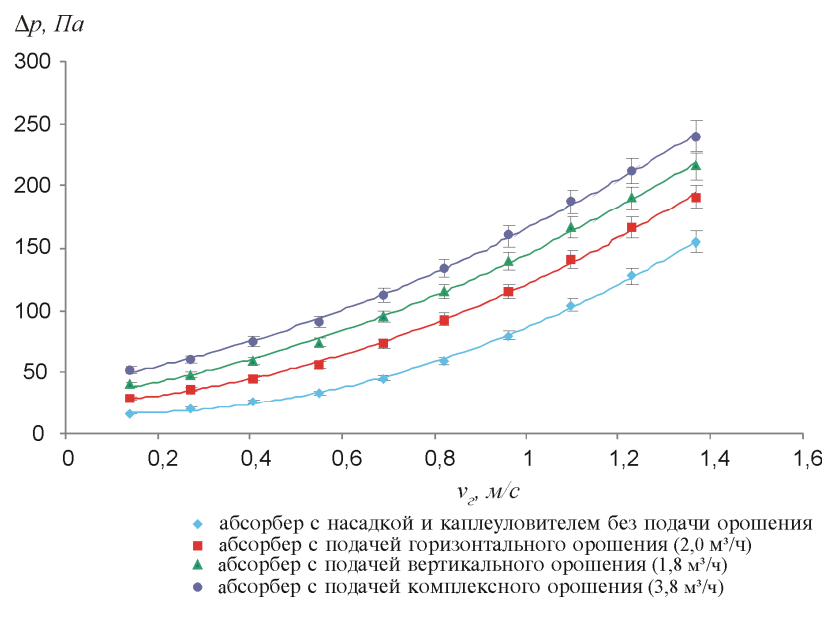

Рис. 4. Зависимость гидравлического сопротивления абсорбера с волокнистой насадкой от линейной скорости газов

Fig. 4. Dependence of hydraulic resistance of absorber with fibrous nozzle on linear gas speed

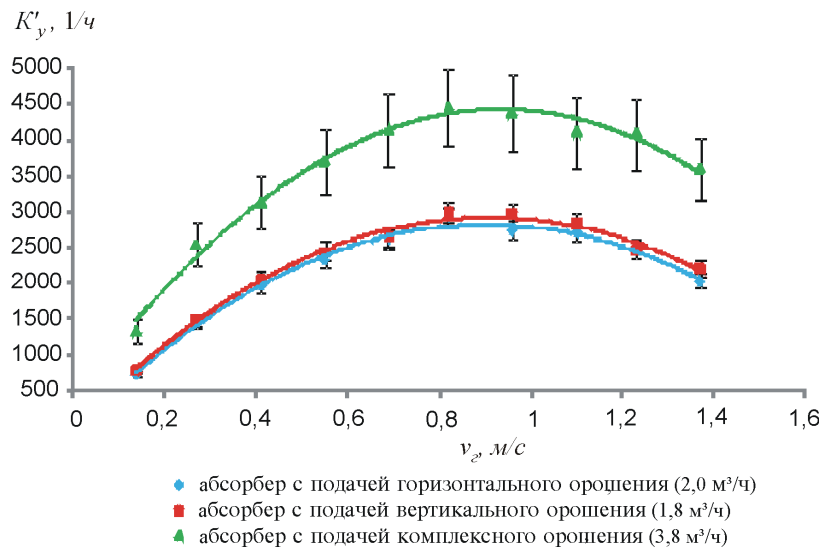

Рис. 5. Зависимость условного объемного коэффициента абсорбции от линейной скорости газов при разных способах подвода орошения

Fig. 5. Dependence of notional volume ratio of absorption on linear gas speed under various types of sprinkling supply

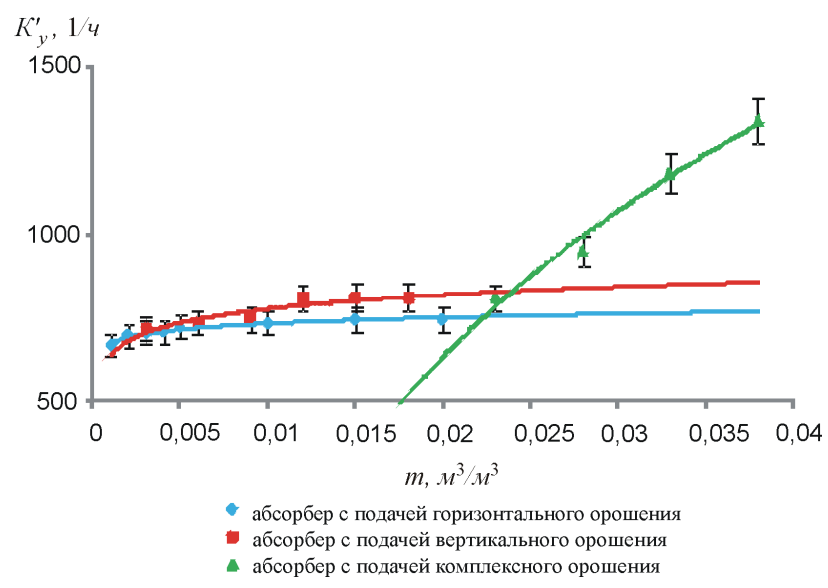

Рис. 6. Зависимость условного объемного коэффициента абсорбции от удельного орошения при разных способах подвода орошения $\left(v_{2}=0,14 \mathrm{~m} / \mathrm{c}\right)$

Fig. 6. Dependence of notional volume ratio of absorption on specific irrigation under various types of sprinkling supply $\left(v_{g}=0.14 \mathrm{~m} / \mathrm{s}\right)$ 


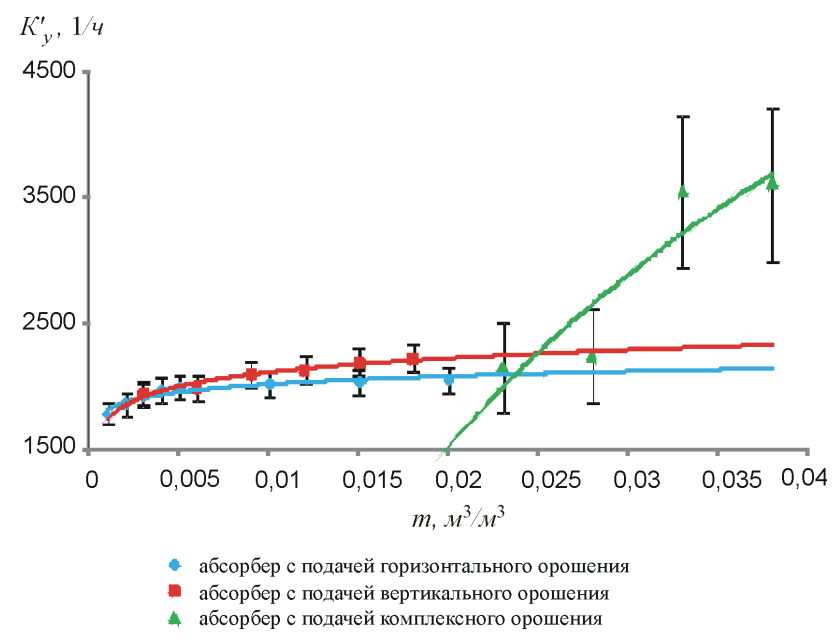

Рис. 7. Зависимость условного объемного коэффициента абсорбции от удельного орошения при разных способах подвода орошения ( $\left.v_{2}=1,37 \mathrm{~m} / \mathrm{c}\right)$

Fig. 7. Dependence of notional volume ratio of absorption on specific irrigation under various types of sprinkling supply $\left(v_{g}=1.37 \mathrm{~m} / \mathrm{s}\right)$

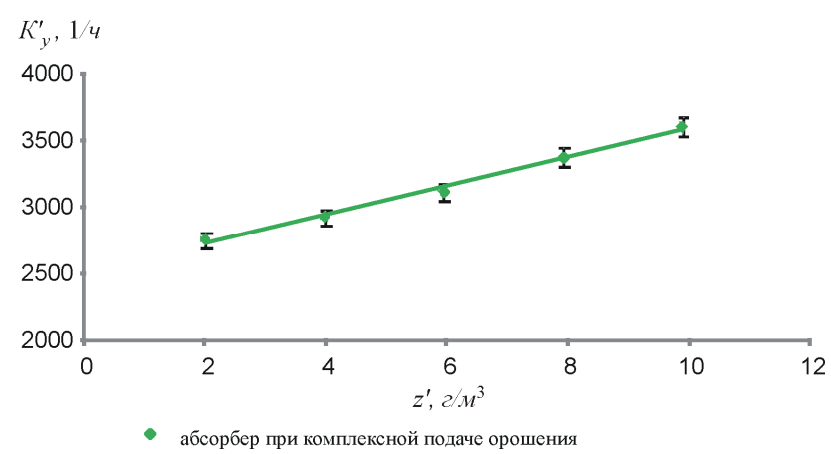

Рис. 8. Зависимость условного объемного коэффициента абсорбции от концентрации $\mathrm{CO}_{2}$ на входе в аппарат при комплексном орошении: одна горизонтальная и три вертикальные форсунки $\left(v_{2}=1,37 \mathrm{M} / \mathrm{c}\right.$; $\left.m=0,0038 \mathrm{~m}^{3} / \mathrm{M}^{3}\right)$

Fig. 8. Dependence of notional volume ratio of absorption on concentration of $\mathrm{CO}_{2}$ at the apparatus inlet under integrated irrigation: one horizontal and three vertical nozzles $\left(v_{g}=1.37 \mathrm{~m} / \mathrm{s}, m=0.0038 \mathrm{~m}^{3} / \mathrm{m}^{3}\right)$

Полученные данные по объемному коэффициенту абсорбции свидетельствуют о его увеличении с возрастанием расхода жидкости на орошение и концентрации углекислого газа на входе в аппарат, что согласуется с литературными данными по абсорбции газов (Коуль $u$ дp. 1967; Рамм 1976; Каган $u$ дp. 2008).

В ходе проведения исследований был определен оптимальный диапазон скоростей газа в свободном сечении аппарата, при котором наблюдаются максимальные значения коэффициента массопередачи (от $0,8$ до $1 \mathrm{M} / \mathrm{c})$.

\section{4. Выводы}

1. Проведенные исследования показали, что аппарат обеспечивает достаточно высокую эффективность (до 78,0\%) улавливания плохо растворимых газообразных компонентов $\left(\mathrm{CO}_{2}\right)$ при сравнительно малом гидравлическом сопротивлении, что немаловажно по энергетическим и экономическим соображениям.

2. Аппарат может быть рекомендован к промышленному применению для комплексной очистки газовых выбросов: от капель туманов и газообразных примесей, включая плохо растворимые.

\section{Литература}

Вальдберг, А. Ю.; Мошкин, А. А; Каменщиков, И. Г. 2003. Образование туманов и каплеулавливание в системах очистки газов. Москва: Издательский Дом «Грааль». $256 \mathrm{c}$.

Вальдберг, А. Ю.; Николайкина, Н. Е. 2008. Проиессы $u$ аппараты защиты окружающей среды. Защита атмосферы. Москва: Изд-во «Дрофа». 239 с.

Вальдберг, А. Ю.; Огурцов, А. В.; Рукина, Н. С. 2004. Абсорбция хорошо растворимых газов в волокнистом фильтре, Химическое и нефтегазовое машиностроение 10: 38-39.

Каган, А. М.; Пушнов, А. С. 2008. Сравнительные характеристики промышленных насадок для процессов тепло- и массообмена, Химическое и нефтегазовое машиностроение 4: 5-7.

Коуль, А. Л.; Ризенфельд, Ф. С. 1967. Очистка газа. Москва: Недра. 394 с.

Кутепов, А. М.; Бондарева, Т. И.; Беренгартен, М. Г. 2005. Общая химическая технология. Москва: Академкнига. $528 \mathrm{c}$.

Лаптев, А. Г.; Фарахов, М. И. 2006. Разделение гетерогенных систем в насадочных аппаратах. Казань: Казан. гос. энерг. ун-т. $342 \mathrm{c.}$

Леонтьев, В. С.; Сидоров, С. И. 2005. Современные насадочные колонны: особенности конструктивного оформления, Химическая промышленность 82(7): $347-356$.

Пушнов, А.; Сакалаускас, А. 2008. Аэродинамика керамических регулярных насадок для тепломассообменных процессов в аппаратах защиты окружающей среды, Journal of Environmental Engineering and Landscape Management 16(1): 30-37.

Рамм, В. М. 1976. Абсорбция газов. Москва: Химия. 656 с.

Родионов, А. И.; Кузнецов, Ю. П.; Соловьев, Г. С. 2005. Защита биосферы от промышленных выбросов. Основы проектирования технологических процессов. Москва: Химия: КолосС. 388 с.

Страус, В. 1981. Промышиленная очистка газов. Москва: Химия. $616 \mathrm{c}$.

Торочешников, Н. С.; Родионов, А. И.; Кельцев, Н. В.; Клушин, В. Н. 1981. Техника защиты окружающей среды. Москва: Химия. 368 с.

Ужов, В. Н.; Вальдберг, А. Ю. 1972. Очистка газов мокрыми фильтрами. Москва: Химия. 248 с.

Krasovickij, J.; Baltrènas, P.; Kolbeschkin, B.; Dobrosotskij, V.; Koltsov, G. 2006. Aerodynamische Verfahren zur Erhöhung der Leistungserzeugund der Entstaubung: Momographie. Vilnius: Tehnika. $352 \mathrm{~s}$. 


\section{ANGLIES DIOKSIDO ABSORBCIJOS PLUOŠTINIO RŪKO SURINKTUVE TYRIMAI}

\section{A. Waldberg, E. Polienova}

S antra ka

Atlikus pluoštinių filtrų pramoninius tyrimus nustatyta, kad šie filtrai, laikomi virš rūko lašelių, efektyviai adsorbuoja dujose esančius nešvarumus. Atsižvelgiant ị tai buvo atliekami tyrimai su natrio šarmo tirpalu ir gauti kiekybiniai $\mathrm{CO}_{2}$ absorbcijos rezultatai. Tirta eksperimentinèmis sąlygomis naudojant prietaisus su pluoštiniu antgaliu. Absorberio tyrimai buvo atliekami Miestų inžinerinès ekologijos laboratorijoje Maskvos valstybiniame aplinkos inžinerijos universitete (AIMVU). Eksperimentinis tyrimas automatizuotas, absorberio režimo parametrai kontroliuojami ir reguliuojami asmeniniu kompiuteriu.

Reikšminiai žodžiai: pluoštinis dangtelis, hidraulinis pasipriešinimas, absorbcija.

\section{STUDY OF CARBON DIOXIDE ABSORPTION IN FIBROUS MIST COLLECTOR}

\section{A. Waldberg, E. Polienova}

\section{Abstract}

Industrial tests of fibrous filters have shown that, above mist drop collecting, they are effective means for adsorption of gaseous impurities. Considering it, there were made tests that enabled reaching quantitative results on $\mathrm{CO}_{2}$ absorption by aqueous solution of sodium. Tests were made on experimental plant using apparatus with fibrous nozzle as its main element. Absorber studies were made in the laboratory of engineering ecology of municipal services at Moscow State University of Environmental Engineering (MSUEE). Experimental plant is automated: controlling and regulation of regime parameters of the absorber are made using the monitor of a personal computer.

Keywords: fibrous nozzle, hydraulic resistance, absorption.

Arnold WALDBERG. Dr Habil, Prof. Moscow State University of Environmental Engineering. Dr Habil of Science (air pollution), Moscow Institute of Chemical Engineering (Russia), 1988. Doctor of Science (air pollution), Leningrad Institute of Technology of Lensovet (Russia), 1967. Employment: Professor of Moscow State University of Environmental Engineering (1999); Professor (1990); Deputy Director General and research officer in NIIOGAZ (1959). Publications: author of 6 monographs, 3 study-guides, 3 reference books, over 230 research papers and 36 inventions. Honorary awards and membership: professor (1990); honoured inventor of Russian Federation; full Member of Russian Ecological Academy. Research interests: air pollution, pollutant properties, pollution control equipment and methods.

Evgenija POLIENOVA. Engineer, doctoral student, Moscow State University of Environmental Engineering. Publications: 1 research paper. Research interests: air pollution, pollution control equipment and methods. 